\title{
Transformações do espaço habitacional ocorridas na arquitetura brasileira do século XIX.
}

\author{
Carlos Alberto Cerqueira Lemos \\ FAU/Universidade de São Paulo.
}

Para que possamos compreender bem os sucessos transformadores do espaço doméstico, especialmente o abrigado, ocorridos entre nós a partir da segunda metade do século XIX, é necessário que tenhamos uma notícia, mesmo que breve, da casa de morada vinda dos tempos de colônia. É o que tentaremos fazer.

É claro que herdamos de Portugal as normas relativas à construção de uma casa de morada. Ocorreu, no entanto, que, em terras portuguesas, devido à imensa variedade de paisagens, cada qual com seus recursos e à presença árabe por mais de seiscentos anos no sul do país, a arquitetura popular assumiu aspectos muito variados, decorrentes tanto da diversidade de técnicas construtivas empregadas como dos climas vários e, o que é importante, como dos programas de necessidade, os norteadores básicos do partido arquitetônico.

O geógrafo português Orlando Ribeiro é quem nos faz, em seus livros, um retrato de Portugal fácil de ser compreendido, para explicar a diversidade das soluções arquitetônicas populares ocorridas naquele país, que pode se orgulhar de possuir várias arquiteturas ditas "vernáculas" concomitantemente.

No sul, que ele chamou de mediterrâneo, embora esteja situado aquém Gibraltar, as casas são de terra, isto é, de taipa de pilão, de adobes ou de tijolos cozidos, todas organicamente aderidas ao relevo do solo. As casas da arquitetura rural, os "montes", são imensas, com grandes telhados cobrindo atividades várias além daquelas do simples morar: Nas grandes planícies de céu sempre azul, casas que se caracterizam pelas chaminés elaboradas. Chaminés que confortavelmente permitiam a culinária, no entanto, não querendo, ou não precisando, corrigir o desconforto de frios invernais, já que ali o clima é sempre brando e amigo do sol. 
No norte, no Portugal Allântico, o solo é pedregoso e caracterizado por montanhas pouco agricultáveis que, para o centeio do pão, exigem terraceamentos e muito adubo. Casas de pedra, quase sempre elevadas do chão. Casas fragmentadas em vários abrigos distintos, um aglomerado de pequenas construções, cada qual com a sua função, ladeando a morada isolada.

Aconteceu, porém, que não houve, como não poderia ter havido, um critério metodológico na seleção dos colonos portugueses destinados a povoar o Brasil. Todos sabemos das ondas migratórias que, aos poucos, foram adensar demograficamente, de início, nossos portos e vilas da marinha e, depois, o sertão, as minas, os latifúndios, rio acima ou em cima da serra. Veio gente do norte, do sul e do centro. Cada pessoa com a sua carga de conhecimentos, com o seu saber fazer, chegando para ficar. Também não houve quem orientasse a respeito das condições ideais de construção, em cada canto da colônia, que tinha uma grandeza continental e uma incrível variedade de recursos da natureza, aptos a satisfazer a técnica construtiva que se quisesse. Era só subir um rio, andar por um atalho, entrar no mato ou percorrer um costão para se satisfazer de uma precisão qualquer numa construção. Ninguém sabia qual a construção ideal para cada sítio.

Como o tempo e o bom senso, quando aliados, resolvem problemas e carências, as coisas aos poucos foram se ajeitando. Quem sabia mexer com pedras tratou de buscar a cal a partir dos sambaquis e quem lavrava a madeira aprendeu logo a trabalhar as madeiras, que a lei d'El Rei separava para os estaleiros, que reparavam as embarcações da "carreira das Indias" e que também faziam os navios e barcaças da cabotagem. Quem não soubesse bater a terra da taipa de pilão, que aprendesse logo, principalmente onde os paus de lei e a pedra fosse de difícil extração, como era o caso de São Paulo. É evidente que, no começo, nos primeiros dias, a tecnologia indígena foi prevalente. O tejupar de palha foi o primeiro abrigo do aventureiro aturdido. $O$ índio ensinou a fazer o rancho, ou methor, deu o material desse rancho; forneceu a primeira comida de farinha de mandioca e até emprestou a mulher, já que os vultos femininos vindos de Portugal eram raríssimos naqueles dias das frotas exploratórias e naqueles meses ou até anos de efetiva posse da terra.

Surgiram, então, as primeiras casas sincréticas nascidas da intervenção do branco nos trópicos. Sincréticas porque os paus vergados, o cipó e a palha aguarirana ou o sapé, ou ainda, as folhas dos coqueiros, em vez de determinarem o espaço promíscuo abobadado da oca indígena, condicionavam espaços cristãos repartidos por paredes selecionadoras de atividades domésticas. Os mocambos do nordeste, pioneiramente estudados por Gilberto Freyre, até hoje subsistem, testemunhando aquela experiência iniciada há quase quinhentos anos.

Estabelecidos os assentamentos definitivos da colônia, tanto nas cidades ou vilas como na roça, alguns elementos, relativos aos programas de necessidades e alguns entraves de ordem técnica, fizeram com que as casas brasileiras, necessariamente, apresentassem características próprias que vieram a singularizá-las, como expressão americana de arquitetura residencial. Dentre vários determinantes dessa individualização arquitetônica, podemos selecionar 
alguns muito importantes, como o clima variadíssimo, as longas distâncias separando os latifúndios das cidades e, também, aspectos comportamentais como a segregação feminina ou o exercício das práticas religiosas, no âmbito doméstico. O interessante é que se conseguiu, em alguns lugares, com certo êxito, a manutenção de partidos arquitetônicos do reino que, de um jeito ou outro, satisfizeram as novas exigências dos peculiares programas da colônia distante. Ao mesmo tempo, a incipiente mão de obra, que se "aclimatou" às condições da colônia, talvez por falta de emulação, se acomodou numa exasperante monotonia edificatória, que a falta de comunicação, com o resto do mundo, transformou numa espécie de marca local, percebida por qualquer forasteiro atento às artes da construção. Deu-se a arquitetura do esperdício; exageradas bitolas das madeiras, que não custavam nada; grossas paredes de grande altura levantadas pela mão de obra escrava. Nenhuma intenção plástica, cuja inquietude viesse pertubar a arrumação das surradas modinaturas. Acomodação, nas casas urbanas, às limitações dos telhados de duas águas, que determinavam, no âmago das construções, as baterias de alcovas escuras e abafadas e isso ficou tão arraigado no ato de morar que, às vezes, a gente fica em dúvida, se aquela planta era daquele jeito, porque o certo era dormir confinado no ar tapado cheirando à fumaça de azeite de peixe ou se dormia ali porque a arquitetura exigia, não dando outra opção.

Mas, voltemos àqueles determinantes acima citados e podemos já falar do clima. O próprio antagonismo, entre os climas do norte e do sul portugueses, nos induz a perguntar, se os variados ares entre o Equador e o Trópico de Capricórnio iriam provocar repetições ou alterações, nos critérios portugueses de obtenção do correto conforto ambiental, face ao binômio calor-frio. Valeria aqui a experiência da pátria-mãe? Não. Aqui, se começou tudo de novo. É que a umidade do ar, essa questão de temperatura relativa, fez com que fossem tomadas providências importantes como, por exemplo, o afastamento da cozinha, coisa que, em Portugal, nunca existiu. Lá a família curte unida o calor do trasfogueiro, depois das refeições invernais. Mesmo no Algarve tépido e de esguias chaminés, o fogão e a cozinha são o centro de interesse da casa. É uma questão cultural que, apesar dos árabes, fez confundir, desde os romanos, fogão e lar; lar no sentido que se quiser dar à palavra. $O$ calor tropical espantou o fogão.

A cozinha apartada, mesmo separada totalmente da casa, foi uma das primeiras características da casa brasileira, desde a primeira construção em que a palha comparecia, pelo menos na cobertura, e, portanto, também sujeita a incêndios. Precaução antes de łudo.

Depois, paredes grossas para obsorver o calor. Altos pés direitos para aumentar o volume de ar. Paredes internas baixas, inclusive nas casa ricas, paredes não de separação efetiva de ambientes, mas de seleção de atividades. Casas de telhas vãs, permitindo que o ar corra pela casa adentro. Forros, só nas alcovas das pessoas enricadas e preconceituosas, que preferiam o desconforto do enclausuramento à promiscuidade olfativa e acústica própria da continuidade espacial. (Este é um assunto discutido até hoje, pois muitos arquitetos modernos desejam essa continuidade, impingindo-a como opção progressista, qualquer que seja a acepção deste termol. 
Foi da Bahia para baixo que surgiu, como que uma necessidade imprescindivel, o alpendre envolvendo a construção. Alpendre, nas faces ensolaradas, impedindo as paredes externas de recéber o calor dos raios do sol. A história da adoção do alpendre, na arquitetura domiciliar brasileira, é meio complicada de entender à míngua de testemunhos daquele tempo antigo. Primeiramente, definamos o que seja alpendre. Essa palavra designa a cobertura situada fora do perímetro das paredes mestras de uma construção. $O$ alpendre pode ser um mero prolongamento do telhado principal, apoiado em sua extremidade inferior por colunas eqüidistantes ou pode ser, também, outra cobertura, situada abaixo do beiral do dito telhado principal. Raramente, encontramos um alpendre verdadeiro na arquitetura portuguesa, a não ser nas capelas rurais. Diga-se de passagem, esses alpendres das pequenas igrejas aldeãs provêm diretamente das galidés, pertencentes às igrejas do princípio do cristianismo, que aproveitaram as basílicas romanas como templos improvisados. Na Península lbérica, onde sempre foram muito comuns, esses alpendres religiosos nunca foram repetidos em projetos de moradias urbanas ou rurais. $O$ que existe muito em Portugal é o espaço aberto reentrante, como se fosse uma sala comum destituída de sua parede externa. Espaço aberto também provido de colunas em sua borda de fora e que pode confundir, na terminologia, as pessoas desavisadas. Espaço aberto reentrante no centro da fachada, provocando uma simetria ao gosto de Palladio, tão comum nas casas populares da Maia ou Murtosa, ou nas casas solarengas minhotas do século XVIII. Aqui encontrável, também, nas casas rurais chamadas de bandeiristas, no planalto à volta de São Paulo colonial. Esse espaço aberto reentrante, primordialmente, era um abrigo temporário de colheitas de cereais e área de distribuição, como se fora um vestíbulo. Nada tem a ver com o clima, ao contrário do alpendre, que sombreia as paredes da casa. O documentarista Debret, com muita acuidade e espírito de observação, notou e escreveu que o alpendre evitava o aquecimento das paredes, tornando o verão suportável dentro da moradia. Ao entardecer, a brisa do mar também fazia do alpendre um local de lazer. Em São Paulo, de muitos dias quentes mas sempre de noites frias, algumas frígidas, - alpendre sempre foi desaconselhado - a taipa haveria de ser aquecida pelo sol para tornar o interior apetecivel durante o sono.

Mas, como o alpendre chegou ao Brasil? Há muitas conjecturas e, na verdade, este breve texło não pode estender-se às minúcias investigativas a respeito de origens de agenciamentos arquitetônicos. Só queremos lembrar que sempre é lembrada a experiência oriental. Certamente, o bangalô indiano influenciou a moda do alpendre na arquitetura dos engenhos de açúcar pernambucanos, devido à presença de técnicos ingleses, durante a instalação da estrada de ferro, somente na segunda metade do século XIX, como recentemente demonstrou o arquiteto Geraldo Gomes. Agora, basta lembrarmos que o alpendre se tornou uma constante brasileira na casa rural.

O exercício da prática religiosa intramuros também propiciou agenciamentos, que podemos chamar de nacionais, porque raros em Portugal. Todas as regiões portuguesas são pontilhadas de pequenas aldeias, mormente 0 centro e o norte e isso faz com que a presença nas igrejas seja muito facilitada, 
devido aos relativamente pequenos percursos em direção à devoção. Em Portugal, qualquer santo na parede ou em pequeno oratório já satisfaz a fé cristã. Lá seria, digamos, um luxo o santo sacrifício da missa a domićlio, o que foi normalíssimo aqui nos engenhos e nas fazendas. Todas as propriedades rurais, até mesmo as pequenas e economicamente inexpressivas, possuiam suas capelas para as missas periódicas do padre itinerante. Muitas, até capelão fixo possuíam. Capela isolada, às vezes, com o seu alpendre fronteiro.

E dizem que aquele costume de segregar as mulheres veio da cultura árabe, o que para nós não faz diferença nenhuma, porque o que vale é o fato, permanentemente observável na casa brasileira colonial, caracterizado pelo programa zeloso, que exigia uma zona íntima, vedada totalmente às visitas $e$ até mesmo à parentela mais afastada. Na sala "de dentro", na cozinha lou mesmo em toda a área de serviço fragmentada em edículas espalhadas pelo vasto quintal, ou pomar, cercado por grades ou muros de taipa) e nas alcovas da sala só tinha acesso a família. Não vamos arrolar quantos depoimentos de viajantes existem falando dessas mulheres ausentes, que ficavam espionando, atrás das frestas das portas e até pelas fechaduras, o movimento dos hóspedes, porque chegaríamos a número exaustivo. Isso já nos indica outra característica de todas as casas brasileiras coloniais, inclusive as urbanas: a existência de duas zonas, a de recepção e a de viver isoladamente.

As longas distâncias, entre propriedades e núcleos urbanos aliadas à vagarenta locomoção a pé ou a cavalo, tornavam necessários os pernoites em meio do caminho. A hospitalidade, longe de ser uma virtude, era uma obrigação social, imprescindivel à sobrevivência. Há mesmo quem vá longe, muito longe, buscar no princípio da vida cristã motivos canônicos ligados à obrigatoriedade da hospedagem do andante, que batesse à porta. Essa hospitalidade brasileira, outrossim, não se limitava só às casas rurais mas, também, às moradas urbanas.

É claro que os hóspedes eram selecionados conforme sua posição social. Os viajantes escravos, os agregados, os humildes sem eira nem beira e os tropeiros com suas cavalgaduras eram alojados em telheiros ou cubículos, no quintal, ao lado dos pastos de pernoite de tropas em trânsito. Os aparentados, os vizinhos conhecidos, os desconhecidos de boa figura e donos de cavalos bem ajaezados ficavam dentro de casa, isto é, embaixo do telhado geral mas, seguramente, apartados da família hospedeira. Daí as duas hipóteses de planejamento: na roça, quartos de hóspedes na faixa de recepção, quase sempre alpendrada; na cidade, alcovas para os de fora, dando portas para a sala da frente. Nas cidades, esse quarto de hóspedes da área social de recepção custou muito a desaparecer. Somente com a facilitação dos meios de transportè, especialmente com a estrada de ferro e com o surgimento de bons hóteis é que a hospedagem nas casas foi diminuindo. Nos ricos palacetes paulistanos, até nos dias da Primeira Guerra, ainda encontramos no térreo, longe dos dormitórios assobradados da família, os quartos para hóspedes amigos. Para quase todos, havendo parentes na cidade, era ofensiva a procura de um hotel.

Pelo que vimos, foi natural, então, a definição, nas casas rurais, de uma faixa fronteira de recepção, composta de quarto de hóspedes, capela e 
"varanda" de receber e comer com as visitas - varanda alpendrada ou entalada entre aquelas outras duas dependências, como na casa bandeirista.

Esse, enfim, o quadro da casa brasileira que, com certa homogeneidade, cobriu o território do Rio Grande do Sul ao Amazonas. Somente variações formais regionalizadas, e já entrado o século XIX, a intenção plástica ainda era compromissada com o estilo pombalino "abrasileirado", sendo os programas de necessidades extremamente semelhantes entre si.Por isso é que Vauthier disse, em meados dos oitocentos, que quem viu uma casa brasileira viu todas.

Os ecos da Revolução Industrial chegaram ao Rio de Janeiro, logo depois do primeiro quartel do século XIX. Foi a Corte de D. Pedro I que começou a tomar conhecimento dos progressos da civilização material e, chegada a metade da centúria, o dinheiro do café fluminense e do açúcar do baixo Paraiba já estava financiando arquitetura eclética residencial, onde esteve expressa toda uma nova arte de construir. Em 1864, inaugurava-se o riquíssimo palácio do Barão de Nova Friburgo, hoje Palácio do Catete, Museu da República, já completamente liberto da moda neoclássica trazida pela Missão Francesa, que ainda transparece, por exemplo, no Palácio do ltamaraty, de 1855. Ao lado dessas construções faustosas, centenas de casas de classe média apareceram, não só mostrando novos gostos mas, também, novas técnicas construtivas destinadas a definir novos espaços para novos programas. Era - Ecletismo, que entrava no Brasil pelo Rio de Janeiro, a porta do Império.

A abastança trazida pelo café chegou a São Paulo pelo Vale do Paraíba e alcançou o interior a partir de Jundiaí. Foi na Capital paulista que as transformações, na arquitetura residencial, se evidenciaram com maior vigor, porque a cidade, até 1860, não passava de um modestíssimo "burgo de estudantes", todo constituído de taipa de pilão. Houve, então, um confronto sem rebuços entre o velho e o novo, entre o caipira e o erudito, aturdindo a todos, que não esperavam tão rápidas alterações, a partir de uma arquitetura insuspeitada porque, em São Paulo, o Neoclássico da Missão ainda não chegara, se algum dia chegou. Tudo ao contrário do Rio, onde as mudanças foram graduais, passando quase que despercebidas pelo povo. Ali, o concurso de fachadas para os edifícios da Avenida Central nada mais foi que a ratificação de um gosto já aceito e aplaudido. Era a modernidade não contestada.

Surtos de riqueza traziam, aqui e ali, verdadeiras explosões de ecletismo em meio tacanho, como aconteceu no brevíssimo ciclo da borracha, em Manaus e Belém. De repente, com o comércio pesqueiro, uma centena de casas magníficas em Laguna, o cenário modesto de nascimento de Anita Garibaldi. E, assim, as modificações na arquitetura domiciliar, que acompanham as transformações do dia a dia familiar, vão surgindo pelo Brasil afora à medida que o tempo e o dinheiro permitam.

Falamos muito em Ecletismo que, como todo o mundo sabe, é uma posição tolerante em relação ao uso simultâneo de estilos, não só em obras vizinhas ou próximas, como foi no começo, mas, inclusive numa mesma construção. Mas, o nosso assunto é a transformação do espaço domiciliar orquestrada por aquele festival estilistico. 
A Revolução Industrial, concomitantemente, provocou mudanças nos programas de necessidades, nos equipamentos e na técnica construtiva. Como aconteceu na quase que imperceptivel e gradual variação estilística, ao longo do tempo, na arquitetura européia. Lá também os progressos da técnica construtiva se sucederam naturalmente, sem causar espanto, ao contrário daqui. Como já vimos, nossa arquitetura nacional pertencia a um patrimônio cultural estruturado, por vínculos e relações necessárias entre aquilo que o meio ambiente oferecia e o "saber fazer" nacional, atendendo a espectativas próprias de uma sociedade praticamente isolada do mundo. Já dissemos, em outro texto, que a casa do Ecletismo nos faz lembrar um disco voador caído de surpresa, numa cidade modorrenta, numa tarde de mormaço, espantando a todos.

Com efeito, os materiais de construção (fora a areia do fundo dos rios) vinham de fora e eram manipulados por mão de obra estrangeira imigrante, para possibilitar plantas e espaços inspirados em revisłas européias, onde haveria de ser satisfeita uma programação nova, alheia ao trivial cotidiano aprendido com os avós e bisavós. Nada a ver com nossa cultura material vigente.

O que possibilitou essa repentina invasão de novidades foi o frete barato, ou mesmo nulo, que cobravam os navios aqui chegados, para voltar entupidos de borracha, de açúcar, de couro, de peixe seco, de cacau e principalmente, ponha-se muito principalmente nisso, de café. Todos os materiais de construção vinham como lastro necessário à correta linha d'água das embarcações. Assim, nossa vida material beneficiou-se com as conveniências do comércio e da estabilidade dos cargueiros transatlânticos.

Vinham de fora até tijolos, tijolos laminados ingleses. $O$ cimento e cal puros chegavam em barricas. Importavam-se ladrilhos, mosaicos, azulejos, telhas de Marselha, placas de mármore, de ardósia. E chapas de ferro, onduladas e galvanizadas. Chapas de zinco puro, de latão de cobre. Canos, tubos, manilhas. Gradis de ferro forjado ou fundido. Papel de parede. Vidro plano liso ou lapidado. Dobradiças, fechaduras, maçanetas. Tintas, betumes e mastiques. E até madeira, o celebrado "pinho de Riga", que já vinha beneficiado por ferramentas industriais aqui nunca suspeitadas. Pinho de talhe doce, leve, perfumado $\mathrm{e}$ isento de bichos daninhos.

A revolução no planejamento das casas deveu-se, então, a esses novos materiais e aos novos conceitos relativos à higiene da habitação. Os médicos, principalmente, aqueles formados na Europa, tinham outras luzes sobre as questões do saneamento e higiene dos lares. As câmaras municipais passaram a ter assessoria de técnicos realmente habilitados, a justificar projetos de lei referentes ao policiamento das novas edificações. Temos notícias de várias câmaras assim amparadas por pareceres bem fundamentados como a de São Paulo, por exemplo, onde há citações eruditas vinculadas à bibliografia moderna. Nos nossos arquivos paulistanos, desde a década de sessenta, iá encontramos profissionais deitando regras, tanto engenheiros como médicos dedicados à saúde pública, ao sanitarismo.

A nova técnica veio de encontro aos reclamos dos recentes conceitos de salubridade doméstica. O tijolo permitiu arcos, abobadilhas, vãos 
maiores e, portanto, janelas de mais luzes e mais próximas umas das outras. Ar e claridade abundantes. Venezianas patrocinando ventilação permanente. Adeus ao mofo. As novas e acessíveis chapas de cobre ou zinco puro permitiram calhas para condução de águas pluviais dos telhados agora recortados, possuindo rincões necessários aos afastamentos laterais, que permitiam a ampla comunicação com o exterior de todos os cômodos da moradia. A casa brasileira estava deixando de ser a "fábrica do medo", no dizer de Guitherme de Almeida. Casas claras.

Construções assoalhadas com porões ventilados. Cozinhas, banheiros, agora internos, áreas descobertas e alpendres com pisos ladrilhados.

No último quartel do século, praticamente, todas as grandes cidades já tinham seus núcleos principais providos de redes públicas de água potável e de linhas de esgoto, fato que garantia a possibilidade da integral execução de modelos europeus chegados em revistas e álbuns de casas aristocráticas. Todos os ricos passaram a ter "salas" de banho e instalações sanitárias, nos andares elevados dos sobrados e contíguas aos dormitórios, banheiros assim possiveis graças aos pisos ladrilhados, apoiados em abobadilhas conseguidas com tijolos, formando pequenos arcos abatidos apoiados em trilhos de estrada de ferro eqüidistantes. E as casas de classe média passaram a conhecer o binômio hidráulico: banheiro-cozinha, dependências necessariamente vizinhas para o aproveitamento de mesmos canos e mesmo esgoto. Tudo uma questão de preço. Só quem podia tinha a latrina longe do fogão.

Mas foi a industrialização de gêneros alimentícios que provocou maiores alterações no planejamento, digamos, no dimensionamento das habitações. Desde os tempos de colônia que as famílias estavam acostumadas a beneficiar os gêneros alimentícios em casa, o que exigia providências responsáveis por grandes áreas construídas, nas zonas de serviços.

Na casa velha, praticamente todos os cereais eram descascados ao lado da cozinha; só o feijão vinha "malhado" da roça, porém muito sujo. $\bigcirc$ arroz era necessariamente pilado no quintal, que ficava revestido da palha seca. O toicinho vindo do açougue, do talho, dizia-se, era derretido horas e "horas no fabrico de banha caseira. O café era também pilado para livrar-se da casca grossa, depois era torrado e depois novamente pilado, para transformarse em pó. Aliás, toda casa, que se prezasse, possuia vários tipos de pilão - os de madeira, madeira que não deixasse cheiro na comida, principalmente na paçoca, os de ferro ou bronze, os almofarizes, que transformavam os temperos em pastas aromáticas salgadas, deixando transparecer o gosto e perfume das ervas e dos "cheiros" verdes. O gral de pedra ou louça para as pomadas medicinais. Enormes tachos e caldeirões. Jiraus para a conservação de toicinho, da carne de sol, do milho pipoca, do sal higroscópico, da lingüiça. Jiraus imensos onde, muitas vezes, o moleque friorento dormia escondido, depois de apagada a candeia. Jirau acessível por escada portátil, escavada em um tronco de coqueiro, à moda dos índios. Grandes prateleiras para os potes de água buscada nos chafarizes, nas cisternas do quintal, as chamadas cantareiras. As gamelas, as masseiras para o pão semanal. As queijeiras cheias de sulcos no tampo inclinado. Queijo feito com o leite transportado em grandes latões, vin- 
dos nos lombos dos burros dos caipiras, que também traziam da roça a lenha para os fogões, sempre mais de um por residência. O fogão da cozinha "suja", no fundo do quintal e o da cozinha "limpa", ao lado da sala de jantar. Grandes armários, enormes depósitos de gêneros por beneficiar.

Na roça, então, as casas possuíam muito mais dependências de serviço, além de cozinhas e despensas urbanas. Lá se fazia a farinha; em aviamentos dispostos em vastos telheiros, se socava o milho embebido d'água nos monjolos. Fazia-se açúcar depois de esfriado o melado grosso - a rapadura era - meio fácil de transportá-lo para as casas urbanas, onde ele era refinado e branqueado nos fogões. Aliás, a cidade já recebia prontas as farinhas de mandioca ou milho. Fornos para as "quitandas" e pães semanais, o que não impedia que houvesse, aqui e ali, uma ou outra padaria.

Já falamos do imigrante, cuja mão de obra possibilitou a novidade da arquitetura eclética e não podemos esquecer que ele também construiu a própria casa. Aliás, foi um precursor nas questões de higiene porque, desde o primeiro dia, fez sua casa isolada lateralmente, com ar e luz em todos os cômodos. Só morou mal nos cortiços levantados pelos capitalistas locais. Capitalistas, que travaram verdadeiras escaramuças com os técnicos da câmara, que desejavam nos códigos de obras proibir os cortiços promíscuos. Acabaram vencendo. Mas o imigrante, quando fazia sua própria casa, estava sabendo muito bem o quanto valiam o ar corrente e a luz do sol. No fundo, isso era uma questão de cultura.

Mas o tema mais interessante, nessa questão relativa às alterações no espaço doméstico da segunda metade do século XIX é aquele relativo ao novo critério de circulação dentro de casa, aos novos modos de superposição de atividades dentro de um mesmo cômodo.

A casa remediada ou rica tradicional tinha o seu centro de interesse situado na grande sala familiar, na varanda também chamada de sala de jantar. A sala-praça, passagem obrigatória entre a rua e a cozinha ou o quintal. A sala onde desembocava o corredor vindo da rua, por onde transitava a criadagem, carregando os potes de água, a lenha dos fogões, os mantimentos, os animais domésticos. Sala onde a família ficava reunida, nas horas de lazer e nos momentos de trabalho caseiro. Sala íntima, antes de tudo, local de acesso às alcovas escuras e, portanto, local de passagem obrigatória dos urinóis pejados dos excretos noturnos.

Com o progresso; essa grande sala das redes e dos vasos de avenca tornou-se aberta a todos devido aos novos modos de convivência, à etiqueta reformulada e podemos dizer que foi o café, no vale do Paraíba fluminense, que abriu a varanda para jantares com convidados de outras famílias. Mas, foram sobretudo os novos inventos, que aperfeiçoaram os aparelhos de iluminação, que provocaram o devassamento dessa área familiar a estranhos. A iluminação farta contribuia para a confraternização. Antes, as luzes trêmulas das candeias; das lamparinas de azeite de peixe para os oratórios; das velas dos castiçais, autoras de compridas sombras nas paredes brancas, mal iluminavam e mais serviam para garantir uma certa inteligibilidade do espaço durante as noites compridas. Por isso dormia-se muito cedo e se acordava com as gali- 
nhas, pois a falta de claridade não estimulava a noitadas, por maiores que fossem os candelabros. Os chamados lampiões belgas de mecha circular e as luminárias a gás trouxeram a luz do dia refletida nas toalhas brancas. Luz que enganava até as mariposas e siriris, que pensavam fosse o sol acordado à noite. No programa de necessidades surgiu uma nova dependência: o quartinho do gás - local onde o carbureto molhado produzia o combustível enviado às salas, por tubos de cobre de pequeno calibre. Recentemente, vimos, num inventário de um Couto de Magalhães referente à casa bandeirista do ItaimBibi, a menção a essa dependência ao lado das velhas taipas.

Essa sala-praça, sala de passagem obrigatória, foi muito bem aceita e amplamente adotada pelos imigrantes italianos $143 \%$ da população paulistana, em 1900), em cujas plantas de casas operárias (operárias porque só de três ou quatro dependências, conforme a denominação da épocal escrevem o termo brasileiro, na acepção brasileira, "varanda", no espaço da grande sala dos fundos, ao lado da qual ficava a cozinha.

A classe alta, no entanto, abandonou a varanda promíscua para assumir o esquema circulatório erudito, aprendido nas viagens das entre-safras a Paris. O chique era morar à francesa e na difusão desse programa destacou-se Ramos de Azevedo que, certamente, foi o grande propagador das plantas contidas nos álbuns de Cesar Daly, o arquiteto registrador dos projetos "modernos" da reformulação urbana, promovida naquela cidade nos tempos de Napoleão III.

O "morar à francesa" pressupunha a divisão da moradia em três zonas distintas: a de estar e receber, a de repousar e a de serviço. Necessariamente devia-se ir de uma para a outra, sem passar pela terceira. Esse critério de distribuição, iá de início, exigia acesso direto da rua à área de serviço e esse fato, aliado à passagem dentro do lote de viaturas e dos cavalos ali estabulados, fez com que naturalmente surgissem recuos laterais. Assim, surgiram os palacetes paulistanos arrodeados de jardins, quase todos providos de porões ditos habitáveis, onde ficavam as dependências de serviço, como lavanderia, despensas, quartos de empregada e, inclusive, a cozinha. Desta, as refeições subiam à sala de jantar por um monta-cargas ou através de uma estreita escada, que ia desembocar numa salinha denominada nas plantas de "service", que ficava contígua à sala de jantar. Até certo ponto, esse agenciamento foi uma espécie de violentação, pois ainda estavam arraigados os hábitos centenários da cozinha ao pé da sala, com a patroa, por mais rica que fosse, circulando daqui pra ali, em permanente contato com as empregadas domésticas, cuja presença ainda estava ligada ao regime servil, embora esses palacetes tenham se proliferado somente a partir de 1890, pelo menos em São Paulo.

Se a cozinha no porão, aos poucos, foi esquecida, a novidade do vestíbulo pegou para sempre, passando a ser chamado de hall depois da Primeira Guerra. O vestíbulo era o centro distribuidor dos passos - ele é que podia garantir a interdependência de cada zona.

A área de estar e de receber é que verdadeiramente se definiu, no último quartel do século XIX, como a derradeira zona a se caracterizar. Antes, as salas eram despojadas e, antes ainda, nos tempos do primeiro imperador, eram quase que vazias, com pouquíssimos móveis e de paredes desnudadas. 
Salas com o essencial e até faltas de ornamentação. De quadros, de tapetes, de reposteiros. Certa vez dissemos mesmo que, a partir da metade do século XIX, acrescentou-se, nas salas, ao útil, o fútil. Nossas dependências de recepção passaram a receber tapetes, cortinas, gravuras, telas e espelhos nas paredes sempre revestidas de papel decorado. Sofás de palhinha, almofadas, toalhas de crochê nos tampos de mármore das mesas de centro, relógios de pêndulo e vasos de flores nos aparadores. Flores que, antes, só existiam nos altares e túmulos. Bibelôs, o supra-sumo da inutilidade. Caixas de música. E pianos. Pianos que também serviam para a ereta acompanhante, que tocava a "Dalila", enquanto a prendada senhorinha declamava o "Navio Negreiro" de Castro Alves, com a voz entrecortada, empostada e até tonitruante, incompatível com a delicadeza de moçoila pálida e de cintura fina. Tertúlias musicais. Risos e charutos só acesos no fumoir, em respeito às senhoras.

Assim, a partir da Independência de 1822, houve a primeira alteração substancial, no espaço domiciliar, que se definiu bem até os dias finais da Primeira Grande Guerra. Depois, vieram outros agentes transformadores, como o cinema, como os arquitetos modernos, mas isso já é outra história.

\section{BIBLIOGRAFIA}

BARROS LATIF, Miriam de. O bomem e o trópico. Uma experiência bra1959 sileira. Rio de Janeiro, Agir.

BUARQUE DE HOLANDA, Sérgio. Caminhos e fronteiras. Rio de Janeiro, José s.d. Olympio.

DEBENEDETTI, E. \& SALMONI, A. Architettura. Italiana a San Paolo. São 1953 Paulo, Instituto Cultural Ítalo-Brasileiro.

FREYRE, Gilberto. Ordem e Progresso. Rio de Janeiro, José Olympio. 1959

FREYRE, Gilberto. Sobrados e Mocambos. Rio de Janeiro, José Olympio. 1951

FREYRE, Gilberto, Mocambos do Nordeste. Rio de Janeiro, publicaçãó n. 1 SPHAN. s.d.

GIDEON, Siegfried. La mecanización toma el mando. Barcelona, Gustavo $1978 \quad$ Gili.

GOMES, Geraldo. Engenho e Arquitetura. São Paulo, FAU/USP. 1990. 
JUREMA, Aderbal. O sobrado na Paisagem Recifense. Recife, Edit. Nordeste. 1952

LEMOS, Carlos A.C. Notas sobre a Arquitetura Tradicional de São Paulo. São 1969 Paulo, FAU/USP.

LEMOS, Carlos A.C. Cozinhas, etc. São Paulo, Perspectiva.

1976

LEMOS, Carlos A.C. Arquitetura Brasileira. São Paulo, Melhoramentos. 1979

LEMOS, Carlos A.C. História da Casa Brasileira. São Paulo, Contexto. 1989

LEMOS, Carlos A.C. Alvenaria Burguesa. São Paulo, Nobel, 2 a edição revista 1989 e aumentada.

LINO, Raul. Casas Portuguesas. Lisboa, Ed. Valentim de Carvalho, $4 a$ ed. 1944

MOUTINHO, Mário. A arquitetura popular portuguesa. Lisboa, Imprensa Uni1979 versitária - Estampa.

OLIVEIRA, Ernesto Veiga de e GALHANO Fernando, Casas esguias do Porto $1986 \quad e$ Sobrados do Recife. Recife, Pool Editorial.

SAIA, Luís. Notas sobre a evolução da morada paulista. São Paulo, Pers1972 pectiva.

VASCONCELLOS, Sílvio de. Vila Rica. Formação de desenvolvimento 1956 residências. Rio de Janeiro, Instituto Nacional do Livro.

VAUTHIER, L.L. Casas de Residência no Brasil, Revista do SPHAN. 1943 


\section{RESUMOS/ABSTRACTS}

Imagem, história e semiótica.

\section{Eduardo Neiva}

Se para entender a imagem é preciso considerátla não apenas em sua dimensão presente de uso, mas a partir de sua perspectiva histórica, devemos examinar criticamente os pressupostos das teorias de cunho histórico. Para tal, esse texto considera o que há de implícito na mais influente teoria histórica da imagem, a Iconologia de Erwin Panossky, situando-a na tradição cognitiva neo-kantiana que confere à linguagem humana o papel de sistema modelador básico para as configurações visuais. Verifica-se, então, que existe no neo-kantismo em suas variações uma teoria dos signos convencionalistas que por estar subjacente é vista e entendida,como inescapável, ao preço de um empobrecimento do entendimento das

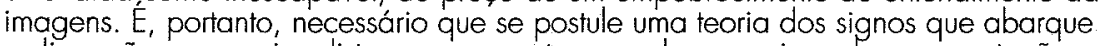
a dimensäo convencionalista, mas que a transcenda, aproximando representaçōes e experiência, graças a um modelo teórico relacional e triádico. O modelo proposto define a imagem como pré-convencional, sendo uma construção hipotética de aspiração analógica, fundada em nossa biologia. Devemos enfrentar o desafio de uma teoria de fundamentação biológica sem a qual inexiste memória e também história das imagens.

UNITERMOS: Iconologia, Semiótica e História

An. MP, NS 1: pg. 11, 1993.

Image, History and Semiotics.

Eduardo Neiva

To understand an image requires not only the present dimension of its use, but also a historical perspective. If that is so, we must examine critically the assumptions of theories that uphold a historical methodology. Therefore, this paper will consider what is implicit in the make-up of one of the most influential historical theory of images, Erwin Panofsky's iconology, placing it in the neo-kantian cognitive tradition that reserves for human language the roles of a basic modulator system dealing with visual configurations. This paper sustains that neo-kantian theories are underlined by a conventionalist theory of signs. Conventionalism impoverishes our understanding of images. Only a triadic model of a relational nature, as opposed to the dyadic structure of conventionalism, could face this problem and then diminish the gap between representation and experience. The image will therefore be defined as pre-conventional, being a hypothetical construction with analogical aspirations sprung from what is biologically given. It is our task to address the challenge of a theory of image derived from our biological foundation without which there would be no memory and no history of images.

UNITERMS: Iconology, Semiotics and History

An. MP, NS 1: pg. 11, 1993

Transformações do espaço habitacional ocorridas na arquitetura brasileira do séc. XIX.

Carlos Alberto Cerqueira Lemos

Depois de referências à arquitetura colonial (inclusive no exame de modelos vernaculares portugueses, da contribuição indígena e da adaptação a condições climáticas, ao isolamento geográfico e a padrổes segregacionistas de comportamentol, o autor descreve os principais traços do padrão difuso de residência rural, assim como de seus equivalentes urbanos. O Ecletismo - com suas raízes externas - é apontado como o principal vetor de transformações, da segunda metade do século XIX até a $1 .{ }^{\circ}$ Guerra Mundial.

UNITERMOS: Espaço doméstico (Brasil, séc.XIX). Arquitetura (Colonial).

An. MP, NS 1: pg. 95, 1993. 
Changes in the domestic space affecting Brazilian 19th. century architecture.

Carlos Alberto Cerqueira Lemos

After a survey of colonial domestic archilecture in Brazil lincluding references to Portuguese vernacular models, indigenous contributions and adaptation to climatic conditions, geographical isolation and seggregative behaviour patterns), the author describes the main features of the diffuse pattern of rural houses, as well as its urban counterparts. Eclecticism - with its alienigenous roots - is considered the most important trend of change from the second half of the 19th - century until the First World War. UNTTERMS: Domestic space (Brazil, 19th. - century). Archictecture (colonial).

An. MP, NS 1: pg. 95, 1993.

Fontes textuais e vida material: observações preliminares sobre casas de habitação nos Campos de Goitacazes, sécs. XVIII ẹ XIX.

Sheila Siqueira de Castro Faria

A autora explora uma rica coleção de inventários dos séculos XVIII e XIX, referentes a habitantes dos Campos de Goitacazes (no atual Norte Fluminense, RI). São propostas inferências sobre vários tópicos: atributos morfológicos e tecnológicos das estruturas, padrōes de afividades. (em particular as produtivas), arranjos espaciais, sistemas de artefatos, relações com a organização familiar, a condição senvil, sistemas de valor, etc. Também se registram as mudanças observadas.

UNITERMOS: Habitação colonial (Brasil). Campos de Goitacazes RJ: organização do espaço rural (éc. $18 / 19)$.

An. MP, NS 1: pg. 107, 1993.

Written sources and material life: preliminary observations on 18 th./19th - century dwelling houses from Campos dos Goitacazes, RJ - Brazil.

Sheila Siqueira de Castro Faria

The author explores a rich collection of 18th.-19th-century inventories regarding inhabitants from Campos dos Goitacazes (the area nowadays known as "Norte Fluminense", State of Rio de Janeiro, Brazill). Inferences are made on several subjects, including morphological and technological attributes of the structures, patterns of activities (particularly the productive ones), spatial ensembles, artifact systems, relationships with family organization, servile condition, valorative systems etc. Observable changes are registered.

UNITERMS: Colonial domestic space (Brazil). Campos dos Goitacazes RJ: organization of rural space (18th.-19th centuries).

An. MP, NS 1: pg. 107, 1993.

Arquitetura eclética no Brasil: o cenário da modernização.

Annateresa Fabris

A autora acentua o significado social e cultural do Ecletismo, além do domínio da arquitetura e do nível dos fenômenos estilísticos. Este quadro lhe permite entender, de um ponto de vista histórico, suas tendéncias cenográficas, o gosto pela magnificência, a expressividade e a monumentalidade, assim como os vínculos com o passado. São então apontados alguns traços específicos do Ecletismo no Brasil, que tem entre seus ingredientes uma atitude anti-colonial. O movimento neoclássico é incluído como manifestação tardia do Ecletismo, que sobreviverá até o estabelecimento de uma nova relação com a modernidade - mediada pela tecnologia UNITERMOS: Ecletismo. Arquitetura eclética (Brasil). Ecletismo, modernidade, modernização. An. MP, NS 1: pg. 131, 1993. 